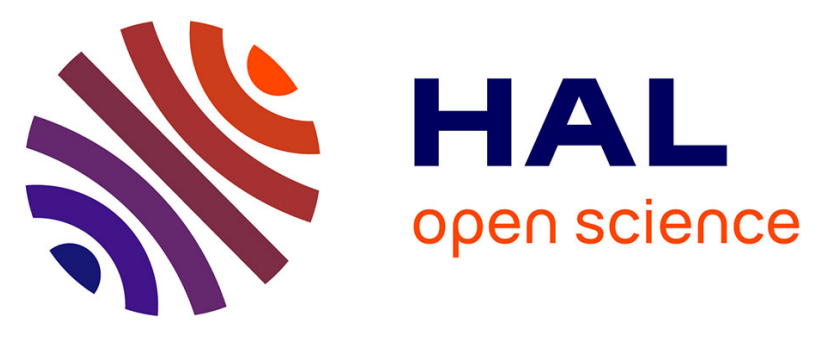

\title{
Detection of human mammaglobin mRNA in serial peripheral blood samples from patients with non-metastatic breast cancer is not predictive of disease recurrence \\ Ana Rita Marques, Elsa Teixeira, Joana Diamond, Helena Correia, Sidónia \\ Santos, Lara Neto, Manuel Ribeiro, Ana Miranda, José Luís Passos-Coelho
}

\section{To cite this version:}

Ana Rita Marques, Elsa Teixeira, Joana Diamond, Helena Correia, Sidónia Santos, et al.. Detection of human mammaglobin mRNA in serial peripheral blood samples from patients with non-metastatic breast cancer is not predictive of disease recurrence. Breast Cancer Research and Treatment, 2008, 114 (2), pp.223-232. 10.1007/s10549-008-0002-9 . hal-00478219

\section{HAL Id: hal-00478219 \\ https://hal.science/hal-00478219}

Submitted on 30 Apr 2010

HAL is a multi-disciplinary open access archive for the deposit and dissemination of scientific research documents, whether they are published or not. The documents may come from teaching and research institutions in France or abroad, or from public or private research centers.
L'archive ouverte pluridisciplinaire HAL, est destinée au dépôt et à la diffusion de documents scientifiques de niveau recherche, publiés ou non, émanant des établissements d'enseignement et de recherche français ou étrangers, des laboratoires publics ou privés. 


\title{
Detection of human mammaglobin mRNA in serial peripheral blood samples from patients with non-metastatic breast cancer is not predictive of disease recurrence
}

\author{
Ana Rita Marques · Elsa Teixeira $\cdot$ Joana Diamond · Helena Correia \\ Sidónia Santos · Lara Neto · Manuel Ribeiro · Ana Miranda • \\ José Luís Passos-Coelho
}

Received: 11 January 2008/Accepted: 1 April 2008/Published online: 13 April 2008

(C) Springer Science+Business Media, LLC. 2008

\begin{abstract}
Introduction Human mammaglobin (hMAM) mRNA is a sensitive and specific marker of breast cancer cells. We evaluated if hMAM mRNA detection in serial peripheral blood samples from non-metastatic breast cancer patients predicts for disease recurrence. Methods Patients scheduled for adjuvant or neoadjuvant chemotherapy were eligible. Serial blood samples were collected up to 5 years, the first before (neo)adjuvant chemotherapy. hMAM gene expression was analysed by RT-PCR. Specificity was evaluated in blood samples from healthy volunteers. A total of 321 patients were included. Results The incidence of pre-chemotherapy hMAM-positive samples was similar in patients who latter experienced cancer recurrence $(22.4 \%)$ and those who remained disease-free (17.9\%; $P=0.46)$. Similarly, the mean number of positive follow-up samples was similar in both groups $(0.15 \pm 0.22$ and $0.13 \pm 013 ; P=0.29)$. Furthermore, there was no difference in disease-free $(P=0.63)$ or overall survival $(P=0.57)$ in patients with and without positive baseline samples or between patients whose follow-up samples were always hMAM negative and those with at least one positive sample. Multivariate survival analysis confirmed that
\end{abstract}

A. R. Marques $(\bowtie) \cdot$ E. Teixeira $\cdot$ J. Diamond $\cdot$ S. Santos L. Neto · J. L. Passos-Coelho

Centro de Investigação de Patobiologia Molecular, Instituto Português de Oncologia de Francisco Gentil, Rua Professor Lima Basto, 1099-023 Lisboa Codex, Portugal

e-mail: armarques@gmail.com

H. Correia

Gabinete de Investigação Clínica, Instituto Português de Oncologia de Francisco Gentil, Lisboa Codex, Portugal

M. Ribeiro · A. Miranda

Registo Oncológico Regional-Sul, Instituto Português de Oncologia de Francisco Gentil, Lisboa Codex, Portugal
hMAM mRNA detection before or after (neo)adjuvant chemotherapy was not predictive of recurrence. Discussion There is no evidence that hMAM mRNA detection at diagnosis or during follow-up predicts for breast cancer recurrence.

Keywords Breast cancer - Mammaglobin - Minimal residual disease

\section{Introduction}

Breast cancer is the most frequent cancer in women in Europe and North America, and the second cause of death in females who develop cancer [1]. At diagnosis, up to $90 \%$ of patients present with disease limited to the breast and axillary lymph nodes. However, in more than a third, the disease will relapse later on due to progression of clinically occult disease.

Tumour size and extent of axillary node involvement are considered the two strongest predictors of breast cancer recurrence, but in some series the detection of bone marrow metastases by immunocytochemistry was also shown to correlate with poor prognosis with a shorter disease-free survival [2]. The detection of circulating tumour cells has been reported by several groups in patients with localised [3-6] and metastatic [7] breast cancer. Circulating tumour cells may lead to the development of metastases and their detection in the peripheral blood of breast cancer patients may thus impact on patient's prognosis [8]. In some series, the number of circulating tumour cells before treatment is an independent predictor of progression-free and overall survival in patients with metastatic breast cancer [7]. However, there is no clear evidence that more aggressive therapy will contribute to improved survival in such patients [9]. 
Several polymerase chain reaction (PCR)-based methods have been used to detect circulating breast cancer cells. There are different molecules that can be used as markers, but an ideal marker should be specific to the tumour cells and not present in normal cells or in the tissue from which the tumour has originated. However, few molecules fulfil these requirements [10]. In contrast to hematological malignancies, solid tumours rarely present specific diagnostic genetic changes. In order to overcome this limitation, tissue-specific markers have been evaluated as potential molecular targets for the detection of occult tumour cells [11-13]. Cytokeratin transcripts (CK19 and CK20) have been widely used in the detection of occult breast cells, but we and others have reported low specificity of these assays [14-16]. The human mammaglobin (hMAM) gene has been proposed as a promising diagnostic marker for breast cancer cells over the last 10 years. This gene, identified by Watson and Fleming in 1996 [17] by differential display PCR, is localised on chromosome 11q13. The protein encoded by hMAM belongs to the uteroglobin/Clara cell family of small epithelial secretory proteins. In contrast to cytokeratins, hMAM was reported to be exclusively expressed in mammary epithelium and overexpressed in some breast cancers, making it a potential useful RT-PCR target for breast cancer cell detection in hematopoietic products $[17,18]$. High levels of hMAM in primary breast tumours reflect a less aggressive tumour phenotype and are correlated with the expression of estrogen and progesterone receptors, diploid DNA content, low Ki67 labelling index, low nuclear grade and absence of axillary nodal invasion [19]. The evaluation of hMAM as a molecular marker of lymph node metastases demonstrated the utility of hMAM-specific PCR in the detection of micrometastases [20-25]. Zach et al. [26] were the first to develop a nested PCR assay for the detection of hMAM mRNA in the peripheral blood of breast cancer patients. They reported that the incidence of detectable hMAM transcripts in peripheral blood was correlated with disease burden: present in 5 of 18 (28\%) patients at diagnosis, in 3 of $53(6 \%)$ with no evidence of disease and in 21 of 43 (49\%) with metastatic disease. Similarly, Cerveira et al. [27] reported that the proportion of patients with breast cancer with detectable hMAM in peripheral blood samples increased with disease stage: $0 \%$ for stage $0,23 \%$ for stage I, 35\% for stage II, 50\% for stage III and $73 \%$ for stage IV.

Five years ago, our group [28] analysed the expression of hMAM transcript by RT-PCR and evaluated the sensitivity and specificity of this molecular marker in the detection of minimal residual disease using patients and volunteers' samples as well as breast cancer cell lines. In addition, we analysed the incidence of hMAM expression in bone marrow, peripheral blood and peripheral blood progenitor cell samples collected from breast cancer patients. We observed that the hMAM mRNA was a sensitive and specific marker of breast cancer cells. However, whether hMAM transcript analysis can detect occult circulating breast cancer cells before the development of overt distant metastases still remains elusive.

In the present study, we performed the prospective evaluation of the contamination of peripheral blood by malignant cells in 321 patients with breast cancer treated with adjuvant or neoadjuvant chemotherapy. The aim of this study was to investigate if the detection of hMAM transcript in the peripheral blood of breast cancer patients (without metastases at diagnosis) was a predictive factor for the development of clinically detectable metastatic disease.

\section{Materials and methods}

Patients' eligibility

Patients were eligible if they had histological or cytological diagnosis of breast cancer, the disease was confined to the breast and the homolateral axillary lymph nodes and if they were to be treated with adjuvant or neoadjuvant chemotherapy.

\section{Controls}

To evaluate the specificity of the assay, serial blood samples from healthy volunteer controls were also studied for hMAM mRNA detection. These controls were selected among the staff of the Centro de Investigação de Patobiologia Molecular (CIPM) and among the physicians of the Hematology and Medical Oncology Services.

\section{Blood sample collection}

Blood samples were to be collected up to 5 years after diagnosis. The first sample was to be collected before the beginning of the adjuvant/neoadjuvant chemotherapy. The remaining samples were collected at each clinic visit: every three months during the first year, every four months during the second year, every six months during the third and fourth year and annually thereafter. This study was approved by the institutional ethics committee and written informed consent was obtained from all participating patients.

\section{RNA extraction}

Total RNA was extracted from nucleated cells of peripheral blood and from T47D human breast cancer cell line, using TRIZOL reagent (Life Technologies, Inc., Gaithersburg, 
MD, USA) according to the manufacturer's protocol. Quantification and purity assessment were performed by optical density measurement at 260 and $280 \mathrm{~nm}$. RNA samples were stored at $-70^{\circ} \mathrm{C}$.

\section{RT-PCR}

Human mammaglobin mRNA expression was analysed by RT-PCR as described previously [28]. Each sample was analysed twice and considered positive if a specific amplification was detected in at least one PCR assay. Negative controls for cDNA synthesis and PCRs, in which the template was replaced by sterile water, were included in each experiment. T47D human breast cancer cell line was used as positive control. T47D total RNA was serially diluted into Esherichia coli tRNA and two concentrations were tested in each PCR: 1 and $10^{-6} \mu \mathrm{g}$ of positive RNA in a total of $1 \mu \mathrm{g} .10^{-6}$ corresponds to the previously established limit of sensitivity [28]. RNA integrity and efficiency of cDNA synthesis were analysed in each sample by performing RT-PCR amplification for the bcr housekeeping gene. Rigorous precautions were taken to eliminate the possibility of false-positive results [29].

\section{Statistical analysis}

Statistical procedures were carried out in order to assess the putative predictive value of hMAM gene expression in detecting breast cancer recurrence. Estimated disease-free and overall survivals for negative and positive hMAM peripheral blood samples were computed with the productlimit estimator (Kaplan-Meier method) and compared with the log-rank test. Missing values for hMAM peripheral blood samples were not imputed. For disease-free survival, recurrence of breast cancer (local, regional or systemic), contralateral breast cancer and death from any cause were considered as events. For survival, death from any cause was considered an event. Chi-Square $\left(\chi^{2}\right)$ and Fisher's Exact tests were used to compare recurrence between patients with negative and positive hMAM samples, and $\chi^{2}$ test for trend was used in case of ordered categories. To explore the effects of multiple predictor independent variables at the same time, a Cox proportional hazards regression model was used. Covariates studied included age, the standard prognostic factors for breast cancer tumor size, axillary lymph node involvement and hormonal receptor status as well as hMAM peripheral blood detection. Statistical analysis was performed using Graph Pad Prism version 2.0 (San Diego, CA, USA) and Intercooled Stata 9.2 for Windows (StataCorp., College Station, Texas, USA).

\section{Results}

Patient population

Three hundred and twenty one patients (320 women and 1 man) with breast cancer were included in the present study. In all patients the disease was limited to the breast and to the homolateral axillary lymph nodes. During the followup (median: 43 months; range: 3-74) 59 of 321 patients (18.4\%) developed metastases and 32 of these patients (54.2\%) died due to disease progression. In two other patients the death was not caused by breast cancer (lymphoma and leukemia, respectively). The 5 year overall and disease-free survival estimates were $85.2 \%$ and $76.9 \%$, respectively (Fig. 1). The recurrence was exclusively local in 6 patients, exclusively distant in 49 patients and combined in 4 patients. Distant recurrences occurred mostly in bone, lymph nodes and liver as the first site of metastatic disease. Six patients were lost to follow-up. Five patients developed a second cancer: contralateral breast cancer in three, lymphoma in one and leukemia in another. Only blood samples collected before recurrence or detection of a second cancer were included in the present analysis.
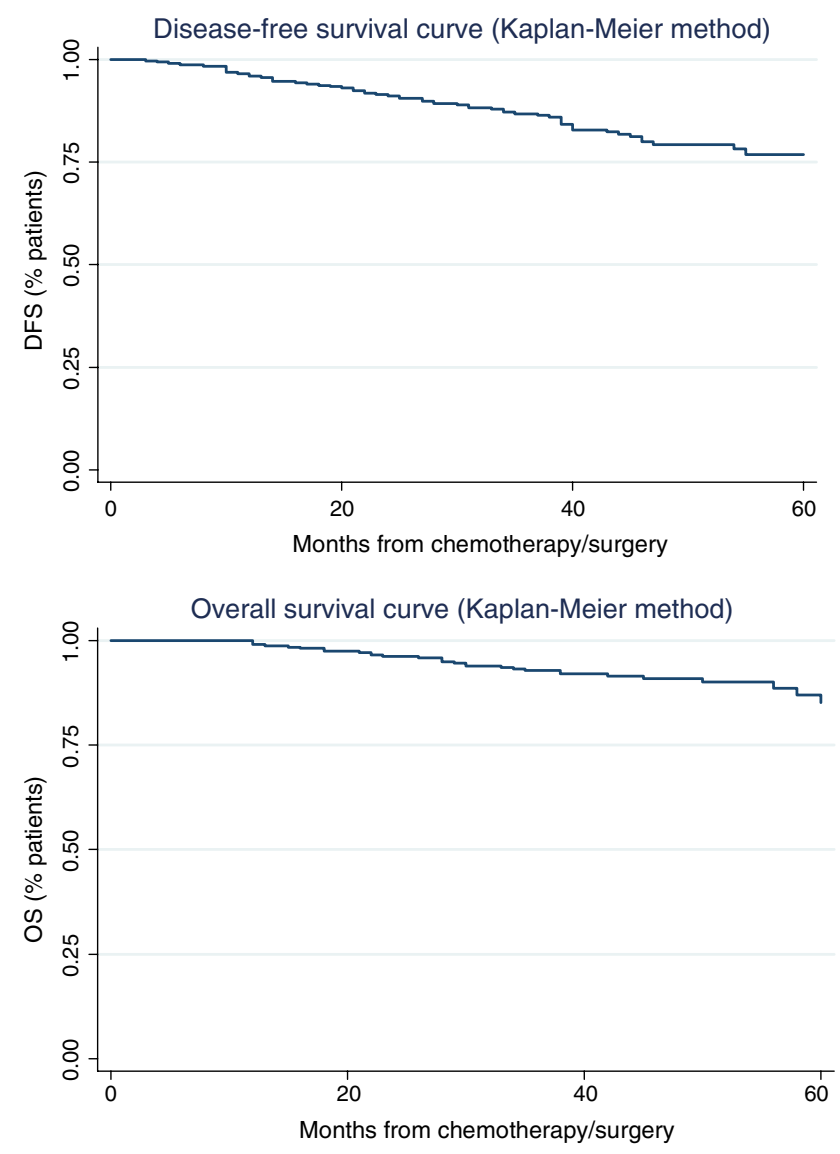

Fig. 1 Kaplan-Meier survival curves for disease-free and overall survival 
The clinicopathological characteristics of patients are presented in Table 1. The median age at diagnosis was 51 years (range: 22-81). Most patients presented with a ductal carcinoma (89.1\%), had high expression of estrogen and/or progesterone receptors $(76.0 \%)$ and no or inconclusive HER-2/neu overexpression (81.3\%). Axillary lymph node involvement was detected in $57.8 \%$ of patients initially treated with surgery and in $71.7 \%$ of those first treated with neoadjuvant chemotherapy followed by surgery.

Peripheral blood samples collection

For logistic reasons, there was no strict adherence to the protocol sample collection schedule. Thus, the time between sample collection as well as the number of samples collected per patient varied between patients.

A total of 2,122 peripheral blood samples were collected during a median follow-up of 43 months (range: 3-74). The median number of peripheral blood samples collected per patient was 7 (range: 1-10).

Analysis of hMAM mRNA expression in peripheral blood samples collected from patients before the beginning of systemic treatment (baseline) and in healthy controls

In 43 patients (13.4\% of study population) the baseline peripheral blood sample, before administration of chemotherapy, was not collected. Overall a total of 52 of 278 (18.7\%) samples were positive for hMAM mRNA. We did not observe a significant difference between the frequency of hMAM-positive baseline samples from patients who later developed a recurrence $(11 / 49 ; 22.4 \%)$ and from patients who have remained disease free $(41 / 229 ; 17.9 \% ; P=0.46)$. Thus, the detection of hMAM transcript in peripheral blood before the administration of (neo)adjuvant systemic chemotherapy did not predict for the development of metastases.

In order to analyse the specificity of RT-PCR assay, peripheral blood from 28 healthy donors ( 3 men and 25 women) were tested. Multiple samples were obtained from most volunteers (median: 2.5 ; range: $1-7$ ) over a median period of 25.5 months (range: $0-47$ ). One sample out of two samples from the same healthy donor was positive. All samples from the remaining controls were negative. Thus the false positive rate among healthy controls was $1.3 \%(1 / 77)$.

Analysis of hMAM mRNA expression in peripheral blood samples collected after systemic (neo)adjuvant chemotherapy

A total of 1844 peripheral blood samples were collected during follow-up. Of those, $241(13.1 \%)$ were positive for
Table 1 Clinicopathological features of patients with breast cancer

\begin{tabular}{lc}
\hline Clinical data & No. of patients $(\%)$ \\
\hline Histology & \\
Ductal & $286(89.1)$ \\
Lobular & $22(6.9)$ \\
Other & \\
pT (Surgery first) & $103(41.7)$ \\
$\mathrm{T}_{1}$ & $130(52.6)$ \\
$\mathrm{T}_{2}$ & $9(3.6)$ \\
$\mathrm{T}_{3}$ & $3(1.2)$ \\
$\mathrm{T}_{4}$ & $2(9.0)$ \\
$\mathrm{T}_{\mathrm{x}}$ & \\
$\mathrm{cT}($ Chemotherapy first) & $4(5.4)$ \\
$\mathrm{T}_{1}$ & $13(17.6)$ \\
$\mathrm{T}_{2}$ & $18(24.3)$ \\
$\mathrm{T}_{3}$ & $33(44.6)$ \\
$\mathrm{T}_{4}$ & $6(8.1)$ \\
$\mathrm{T}_{\mathrm{x}}$ &
\end{tabular}

No. positive axillary lymph nodes (Surgery first)

0

103 (41.7)

$1-3 \quad 80(32.4)$

$4-9 \quad 45(18.2)$

$\geq 10 \quad 16(6.5)$

Unknown 3 (1.2)

No. positive axillary lymph nodes (Chemotherapy first)

$0 \quad 17(23.0)$

$1-3 \quad 16(21.6)$

4-9 $17(23.0)$

$\geq 10 \quad 10(13.5)$

Unknown 14 (18.9)

Estrogen and/or progesterone receptors

Positive

$244(76.0)$

Negative

$71(22.1)$

Unknown

6 (1.9)

HER-2/neu overexpression ${ }^{\mathrm{a}}$

Positive 44 (13.7)

Negative 156 (48.6)

Inconclusive $\quad 35(10.9)$

Unknown $\quad 86(26.8)$

Grade

$\mathrm{G}_{1} \quad 27(8.4)$

$\mathrm{G}_{2} \quad 168(52.3)$

$\mathrm{G}_{3} \quad 49$ (15.3)

Unknown 77 (24.0)

Chemotherapy

Adjuvant 247 (76.9)

Neoadjuvant 74 (23.1)

Hormonal therapy

Yes 243 (75.7)

No 78 (24.3) 
Table 1 continued

\begin{tabular}{lc}
\hline Clinical data & No. of patients $(\%)$ \\
\hline Surgical procedure & \\
MRM & $161(50.2)$ \\
BCS & $156(48.6)$ \\
No surgery & $4(1.2)$ \\
Radiotherapy & \\
Yes & $83(25.9)$ \\
No & $238(74.1)$
\end{tabular}

a Positive-Immunohistochemistry $3+$ and/or gene amplification by FISH; Inconclusive-Immunohistochemistry $2+$ without confirmation by FISH

${ }^{b}$ Four patients did not have surgery. MRM-Modified radical mastectomy; BCS-Breast conservation surgery

hMAM transcript. One hundred and seventy seven $(55.1 \%)$ patients had at least one positive sample during the follow-up.

To investigate the impact on the risk of relapse of the detection of mammaglobin transcript in serial blood samples from patients with breast cancer, we calculated the ratio between the total number of positive samples and the total number of analysed samples per patient, which we denominated hMAM SCORE. The hMAM SCORE could not be calculated in 6 patients, because no follow-up samples were collected up to the date of recurrence or last follow-up. The hMAM SCORE was not significantly different between patients who relapsed (mean: $0.15 \pm 0.22 ; N=54$ ) and patients who remained disease free (mean: $0.13 \pm 0.13 ; N=261 ; P=0.29$ ). Thus the frequency of the detection of hMAM transcript in blood samples after the administration of (neo)adjuvant systemic chemotherapy is not associated with the development of disease recurrence. In only 10 of $54(18.5 \%)$ patients that relapsed, was the hMAM transcript detected in the last blood sample collected before recurrence, with a median time between sample collection and the detection of disease recurrence of 5 months (range: 1-24). Seven of these 10 patients $(70 \%)$ have already died as a result of disease progression. In contrast hMAM mRNA was found in the most recently collected sample of 20 of $261(7.7 \%)$ patients that have remained disease free $(P=0.01)$.

To analyse further the clinical relevance of a positive hMAM sample collected during the follow-up, we evaluated the predictive value for disease recurrence of the detection of any single positive peripheral blood sample and of two consecutive positive peripheral blood samples. In only 7 of 177 (4\%) positive follow-up samples did breast cancer recurrence develop before the collection of the next peripheral blood sample. Furthermore, if two consecutive
Table 2 Multivariate analysis models for disease-free survival

\begin{tabular}{|c|c|c|c|}
\hline Variable & Hazard ratio & 95\% C.I. & $P$ value \\
\hline Age at diagnosis & 0.970 & $0.945-0.995$ & 0.021 \\
\hline T stage & 1.919 & $1.395-2.640$ & $<0.001$ \\
\hline Positive lymph nodes & 1.127 & $1.075-1.183$ & $<0.001$ \\
\hline Hormonal therapy & 0.270 & $0.132-0.555$ & $<0.001$ \\
\hline hMAM at baseline & 0.989 & $0.445-2.200$ & 0.978 \\
\hline Age at diagnosis & 0.966 & $0.937-0.995$ & 0.023 \\
\hline T stage & 1.932 & $1.358-2.750$ & $<0.001$ \\
\hline Positive lymph nodes & 1.126 & $1.062-1.194$ & $<0.001$ \\
\hline Hormonal therapy & 0.180 & $0.079-0.410$ & $<0.001$ \\
\hline hMAM- up to 6 months & 0.930 & $0.356-2.430$ & 0.883 \\
\hline Age at diagnosis & 0.962 & $0.938-0.988$ & 0.004 \\
\hline T stage & 1.885 & $1.372-2.589$ & $<0.001$ \\
\hline Positive lymph nodes & 1.142 & $1.088-1.990$ & $<0.001$ \\
\hline Hormonal therapy & 0.177 & $0.088-0.356$ & $<0.001$ \\
\hline hMAM-up to 12 months & 0.921 & $0.483-1.757$ & 0.804 \\
\hline Age at diagnosis & 0.964 & $0.940-0.988$ & 0.004 \\
\hline $\mathrm{T}$ stage & 1.817 & $1.342-2.460$ & $<0.001$ \\
\hline Positive lymph nodes & 1.132 & $1.080-1.184$ & $<0.001$ \\
\hline Hormonal therapy & 0.187 & $0.094-0.370$ & $<0.001$ \\
\hline hMAM- up to 18 months & 0.675 & $0.363-1.254$ & 0.214 \\
\hline Age at diagnosis & 0.965 & $0.941-0.989$ & 0.006 \\
\hline $\mathrm{T}$ stage & 1.822 & $1.337-2.484$ & $<0.001$ \\
\hline Positive lymph nodes & 1.134 & $1.082-1.188$ & $<0.001$ \\
\hline Hormonal therapy & 0.187 & $0.095-0.370$ & $<0.001$ \\
\hline hMAM- up to 24 months & 0.610 & $0.332-1.120$ & 0.111 \\
\hline Age at diagnosis & 0.964 & $0.940-0.989$ & 0.004 \\
\hline T stage & 1.823 & $1.338-2.483$ & $<0.001$ \\
\hline Positive lymph nodes & 1.135 & $1.084-1.190$ & $<0.001$ \\
\hline Hormonal therapy & 0.172 & $0.086-0.344$ & $<0.001$ \\
\hline hMAM- up to 36 months & 0.496 & $0.272-0.905$ & 0.022 \\
\hline Age at diagnosis & 0.964 & $0.940-0.988$ & 0.004 \\
\hline T stage & 1.806 & $1.325-2.463$ & $<0.001$ \\
\hline Positive lymph nodes & 1.136 & $1.084-1.190$ & $<0.001$ \\
\hline Hormonal therapy & 0.175 & $0.087-0.349$ & $<0.001$ \\
\hline hMAM- up to 48 months & 0.529 & $0.291-0.963$ & 0.037 \\
\hline
\end{tabular}

Age (in years) as a continuous variable; primary tumour stage according to TNM classification; lymph node positivity categorized as negative, 1-3, 4-9 and 10 or more positive nodes; hormonal therapy as adjuvant treatment as yes or no; hMAM as at least one positive versus all negative peripheral blood samples collected at baseline and at different follow-up cut-off periods (in months). C.I. as confidence interval

hMAM positive samples are considered, in only 1 of 28 $(4 \%)$ instances did the disease recur before the collection of the next follow-up samples. 
Correlation between the detection of hMAM mRNApositive cells in peripheral blood samples and the clinicopathological characteristics of patients

There was no association between the presence of hMAM mRNA-positive circulating cells before the administration of chemotherapy and clinicopathological characteristics such as age at diagnosis, $\mathrm{T}$ stage, axillary lymph node involvement, hormone receptor status or tumour grade (data not shown). In contrast, almost all patients (34/36; 94\%) with HER-2 positive tumours had baseline peripheral blood samples negative for hMAM mRNA, compared to $77 \%$ of patients with HER-2 negative tumours (104/135; $P=0.02)$.

To further investigate the clinical impact of hMAM expression in blood samples collected after the administration of systemic therapy, we analysed the correlation between the hMAM SCORE and clinicopathological features. There was no association between the hMAM SCORE and age at diagnosis, $\mathrm{T}$ stage, hormone receptors expression, HER-2 status and tumour grade (data not shown). In contrast, there was an association of the hMAM SCORE and axillary lymph node involvement, but only for the subgroup of patients initially submitted to surgery. The mean hMAM SCORE was 0.23 for patients with $\geq 10$ positive nodes and 0.11 for negative nodes, 0.14 for $1-3$ positive nodes and 0.13 for $4-9$ positive nodes $(P=0.03)$. However, no such association was documented for the subgroup of patients who received neoadjuvant chemotherapy first.

\section{Survival analysis}

The Kaplan-Meier estimates of overall survival and diseasefree survival for patients with hMAM mRNA-positive and negative baseline peripheral blood samples were not different (Fig. 1, $P=0.57$ and $P=0.63$, respectively). Furthermore, we did not observe significant differences in disease-free survival between patients whose follow-up samples were always hMAM negative and patients with at least one hMAM positive sample, when considering samples collected at different cut-off time points up to 24 months after diagnosis. However when samples collected up to 36 and 48 months were included, hMAM mRNA positivity was associated with improved overall and disease-free survival $(P \leq 0.05)$, contrary to the study hypothesis and difficult to understand biologically. Disease free survival curves stratified for hMAM positivity at baseline, up to 18 months and up to 48 months are shown in Fig. 2.

Multivariate analysis for disease-free survival

A Cox regression multivariate analysis was performed to estimate the impact on disease-free survival of several
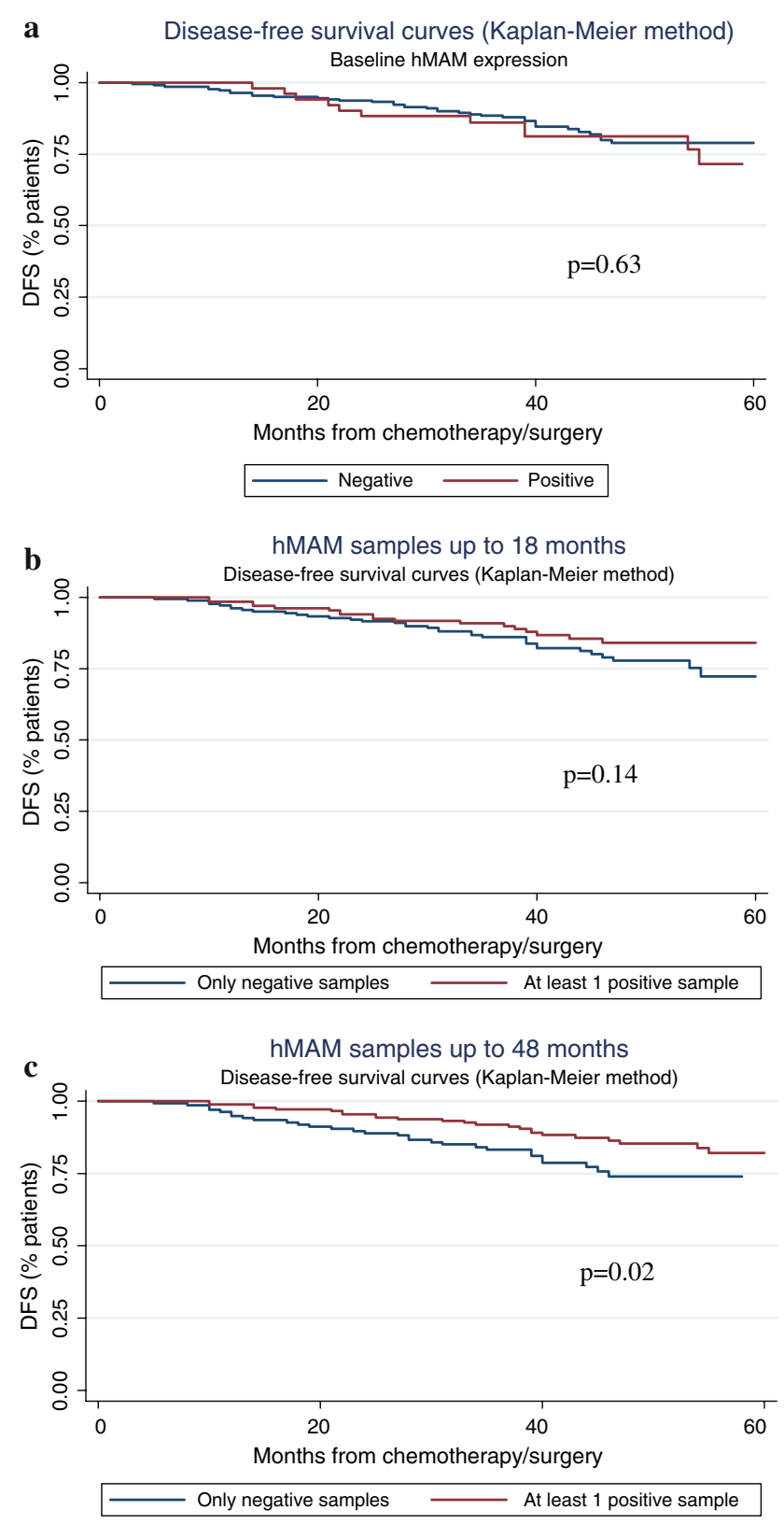

Fig. 2 Kaplan-Meier disease-free survival curves stratified by hMAM mRNA detection. Kaplan-Meier disease-free survival curves for patients whose peripheral blood samples were always hMAM mRNA negative versus patients with at least one hMAM mRNA positive sample collected at baseline (a), up to 18 (b) or up to 48 (c) months after diagnosis. Comparisons of survival curves by log-rank test

clinicopathologic parameters and of the mammaglobin transcript detection in peripheral blood. Several models were studied to incorporate hMAM results up to several different follow-up time points (Table 2). As expected, age at diagnosis, $\mathrm{T}$ stage, axillary lymph node involvement and hormonal therapy were significant independent prognostic factors in all models. In contrast, the detection of hMAM 
mRNA before the administration of systemic therapy (baseline), as well as in at least one blood sample collected after (neo)adjuvant chemotherapy, were not independent prognostic factors for disease-free survival. Furthermore, a positive hMAM blood sample collected up to 36 or 48 months after diagnosis was an independent prognostic factor for better disease-free survival, again contrary to study hypothesis.

\section{Discussion}

Circulating tumour cells can be detected in the peripheral blood of patients with a wide range of malignant tumours of epithelial origin. These cells are present not only in patients with metastatic disease, but also in those whose tumours are apparently localised [30]. This is also observed in breast cancer, where malignant cells seem to spread into the bloodstream in early stages of tumour development [31, 32]. Many patients subsequently relapse at distant sites despite adequate local treatment, presumably as a result of undetected spread of the tumour cells before the removal of the primary tumour [30].

RT-PCR has been used for the detection of specific tumour cell markers, thus indicating the presence of circulating breast tumour cells in the blood, with varying degrees of sensitivity and specificity [33]. The hMAM gene was described to be a potentially specific marker for the detection of circulating breast cancer cells [34]. However, the clinical relevance of the detection of hMAM positivetumour cells in the peripheral blood of patients with localised breast cancer still remains elusive, since several papers report conflicting results [35-37].

In the present study we performed the prospective analysis of hMAM mRNA detection in serial samples of peripheral blood collected from patients with non-metastatic breast cancer. We observed high degree of specificity of the RT-PCR assay, since there was only a single positive result among 77 healthy volunteers' peripheral blood samples. Despite the high specificity of hMAM RT-PCR assay, the induction by several cytokines of mammaglobin expression in cell lines, in bone marrow and in peripheral stem cells from patients without epithelial cancer has been reported [38]. This may explain the occurrence of a single false-positive result in a healthy donor sample. In addition, other groups reported the detection of mammaglobin transcript in non-breast tissues, such as ovary, uterus, cervix and sebaceous glands [37, 39, 40].

We detected the hMAM transcript in 52 of 278 (18.7\%) patients, before the administration of any adjuvant or neoadjuvant therapy. Thirty eight of 212 (17.9\%) patients with operable breast cancer presented hMAM positivebaseline sample. Similarly, Ntoulia et al. [41] also reported the expression of hMAM mRNA in 14/101 (13.9\%) peripheral blood samples collected before the start of adjuvant chemotherapy, from patients with operable breast cancer. In contrast, Cerveira et al. [19] documented peripheral blood hMAM positivity in $41 \%$ of breast cancer patients, by one-step RT-PCR. They hypothesized that the low percentages of positive results reported in other studies could be related to low sensitivity of the RT-PCR assay. However, our assay has a limit of detection of one tumour cell in $10^{6}$ hematological control cells when using the T47D cell line [28], which was similar to the reproducible limit of detection obtained by Cerveira et al. [27]. Needless to mention, the absence of hMAM mRNA in blood samples does not exclude the presence of circulating tumour cells. The detection of these cells may depend on the number of cancer cells present in the blood and also on the hMAM expression level by individual cells [42]. Recently, quantitative real-time fluorescence-based RT-PCR has become the ideal method for the detection of RNA [43]. Some studies have applied this methodology in the analysis of mammaglobin mRNA expression in peripheral blood samples of breast cancer patients and still reported low sensitivity [36, 44]. Although real-time RT-P CR allows the quantification of the transcript of interest, conventional RT-PCR is still a good method for a prospective study with a high number of samples. At the time this study started, quantitative real-time fluorescence-based RT-PCR was not widely available. When this technology became available at our center, we decided not to change the methodology half-way into the study, without strong evidence that switching to quantitative real-time RT-PCR would dramatically alter the test sensitivity and specificity. In this study, the detection of the mammaglobin transcript in peripheral blood of breast cancer patients before the start of systemic therapy was not associated with clinical relapse (22.4\% of positivity in patients who relapsed and $17.9 \%$ in patients who remained disease free; $P=0.46)$. Furthermore, the Kaplan-Meier estimates of overall $(P=0.57)$ and disease-free survival $(P=0.63)$ rates for hMAM transcript positive and negative patients were not different. Our results are partially concordant with Ntoulia et al. [41], who observed significant differences in the disease-free survival, but not in overall survival, according to hMAM detection.

To evaluate the impact of the detection of the mammaglobin transcript in blood samples before systemic therapy, we analysed the association between several clinicopathological characteristics and the hMAM mRNA detection. We did not observe an association between hMAM expression and several parameters such as age at diagnosis, $\mathrm{T}$ stage, number of positive axillary lymph nodes, hormone receptor positivity or tumour grade, as previously reported $[42,45]$. However, we detected an 
inverse association between mammaglobin mRNA expression in blood baseline samples and HER-2 overexpression or amplification in tumours. This is in contrast with the association of HER-2 overexpression and tumour aggressiveness [46] but in agreement with the reported lower expression of hMAM by breast tumour cells with a more aggressive phenotype documented by no expression of hormone receptors and high nuclear grade [19]. Thus, tumours with HER-2 overexpression may express lower or undetectable levels of hMAM transcript, which has not been studied before.

Not only didn't we document an association between hMAM detection in peripheral blood at diagnosis and disease recurrence or survival, we did not document such an association with the detection of mammaglobin transcript in blood samples collected after the administration of systemic (neo)adjuvant chemotherapy either. Patients who relapsed had a similar hMAM SCORE to patients who remained in remission (mean: $0.15 \pm 0.22 ; N=54$ vs. $0.13 \pm 013$; $N=261 ; P=0.29)$. Similarly, there was no difference in disease-free survival between patients whose samples were always hMAM negative and patients with at least one hMAM positive peripheral blood sample, when samples collected up to 24 months after diagnosis were analysed $(P=0.05)$. If later samples were included in the analysis, up to 48 months, patients with at least one hMAM positive sample had better disease-free survival than patients who never had hMAM positive blood samples, contrary to the study hypothesis. Mammaglobin expression by breast cancer cells seems to be correlated with indicators of better prognosis [19]. This may explain why we observed that hMAM positivity in baseline peripheral blood samples was more frequent in patients with HER2-negative tumours than in patients harbouring tumors with HER2 overexpression/ amplification. Thus, hMAM-positive circulating tumour cells may be a surrogate for a more indolent disease with a delayed risk of recurrence. However, Mikhitarian et al. [47] reported that the overexpression of hMAM in peripheral blood samples collected before surgery was significantly associated with high tumour grade and showed a trend towards estrogen receptor-negative high risk breast cancer. Alternatively, since it has been reported that apoptotic cells represent the majority of circulating tumor cells in patients with breast cancer [48], a potential explanation for the association of hMAM positivity in the blood and improved prognosis could be that hMAM detection is a marker of enhanced chemotherapy effect, leading to increased likelihood of circulating apoptotic tumor cells. However, we have no data to support that the hMAM-positive circulating tumor cells detected by our assay are apoptotic. Using Cox proportional hazards model, after adjustment for significant clinical and pathologic parameters, there was no association of either hMAM mRNA detection in the baseline blood sample or the follow-up samples collected after the administration of (neo)adjuvant chemotherapy and the disease-free survival.

We investigated the association between the hMAM detection and clinicopathological features of the disease. Other than the presence of 10 or more positive axillary lymph nodes, there was no association between hMAM SCORE and clinical or pathologic parameters. Since the number of positive axillary lymph nodes is the most significant poor prognostic factor for patients with early-stage breast carcinoma [49, 50], an association with hMAM positivity in peripheral blood would be anticipated. However, this association was only documented among patients initially treated with surgery and not among patients for whom neoadjuvant chemotherapy was the first treatment modality. Thus, this association could be spurious and the statistically significant result dependent from multiple comparisons. Similarly, Ignitiadis et al. [6] using CK-19 peripheral blood detection by real-time RT-PCR also failed to document any association between clinicopathologic variables and CK-19 positive peripheral blood samples collected prior to adjuvant chemotherapy. While axillary lymph node involvement predicts for distant metastases, many patients with breast cancer develop systemic disease in the absence of regional node involvement. As discussed by Pantel and Brakenhoff [51], breast cancer cells may disseminate from the primary tumor to axillary lymph nodes and distant metastatic sites by different routes. These separate routes may depend on different chemokine receptor-ligand axis. For instance CXCL12, the ligand for CXCR4, is strongly expressed in lung, liver, bone marrow and lymph nodes while CCL21, the ligand for CCR7, is strongly expressed in lymph nodes [52]. In a melanoma model, transfection of CCR7 promotes lymph node metastases while transfection of $\mathrm{CXCR} 4$ promotes lung metastases [53, 54]. These data indirectly support the absence of relationship between axillary lymph node involvement and detection of circulating breast cancer cells.

In conclusion, despite high specificity of hMAM mRNA detection in peripheral blood samples, we found no evidence that the detection of hMAM in peripheral blood samples either at diagnosis or during follow-up is predictive of breast cancer recurrence. Contrary to the study hypothesis, the detection of at least one positive hMAM blood sample during extended follow-up (beyond 24 months) seemed to be protective against breast cancer recurrence. Since only one blood sample collected from healthy controls was positive for hMAM mRNA, confirming the previously reported specificity of the test, the biological interpretation of transient positive results in these breast cancer patients remains unclear. 
Acknowlegements This work was supported by a grant from "Fundação para a Ciência e Tecnologia" (PRAXIS/P/SAU/14037/ 1998) and by a Terry Fox grant from "Liga Portuguesa Contra o Cancro". We are grateful for the collaboration and help of the nurses of the Outpatient Department and Day Hospital of the Instituto Português de Oncologia Francisco Gentil, in Lisboa. This paper was written accordingly to the REMARK criteria for tumour marker studies, as requested [55].

\section{References}

1. Jemal A, Siegel R, Ward et al (2007) Cancer statistics, 2007. CA Cancer J Clin 57:43-66

2. Diel IJ, Kaufmann M, Costa SD et al (1996) Micrometastatic breast cancer cells in bone marrow at primary surgery: prognostic value in comparison with nodal status. J Natl Cancer Inst 88:1652-1658

3. Mansi JL, Gogas H, Bliss JM et al (1999) Outcome of primarybreast cancer patients with micrometastases: a long-term followup study. Lancet 354:197-202

4. Solomayer EF, Diel IJ, Salanti G et al (2001) Time independence of the prognostic impact of tumor cell detection in the bone marrow of primary breast cancer patients. Clin Cancer Res 7:4102-4108

5. Janni W, Rack B, Schindlbeck C et al (2005) The persistence of isolated tumor cells in bone marrow from patients with breast carcinoma predicts an increased risk for recurrence. Cancer 103:884-891

6. Ignatiadis M, Xenidis N, Perraki M et al (2007) Different prognostic value of cytokeratin-19 mRNA-positive circulating tumor cells according to estrogen receptor and HER2 status in earlystage breast cancer. J Clin Oncol 25:5194-5202

7. Cristofanilli M, Budd GT, Ellis MJ et al (2004) Circulating tumor cells, disease progression and survival in metastatic breast cancer. N Engl J Med 351:781-791

8. Pantel K, Cote RJ, Fodstad O (1999) Detection and clinical importance of micrometastatic disease. J Natl Cancer Inst 91:1113-1124

9. Carrick S, Parker S, Wilcken N et al (2005) Single agent versus combination chemotherapy for metastatic breast cancer. Cochrane Database Syst Rev Apr 18, CD003372

10. Jiang WG, Martin TA, Mansel RE (2002) Molecular detection of micro-metastasis in breast cancer. Crit Reev Oncol Hematol 43:13-31

11. Pantel K (1996) Detection of minimal residual disease in patients with solid tumors. J Hematother 5:359-367

12. Raj GV, Moreno JG, Gomella LG (1998) Utilization of polymerase chain reaction technology in the detection of solid tumors. Cancer 82:1419-1442

13. Lambrechts AC, Van't Veer LJ, Rodenhuis S (1998) The detection of minimal numbers of contaminating epithelial tumor cells in blood or bone marrow: use, limitations and future of RNAbased methods. Ann Oncol 9:1269-1276

14. Jung R, Petersen K, Krüger W et al (1999) Detection of micrometastasis by cytokeratin 20 RT-PCR is limited due to stable background transcription in granulocytes. $\mathrm{Br} \mathrm{J}$ Cancer 81:870-873

15. Chamelovier P, Mongelard F, Seigneurin D (1999) CK20 gene expression: technical limits for the detection of circulating tumor cells. Anticancer Res 19:2073-2078

16. Silva AL, Diamond J, Silva MR, Passos-Coelho JL (2001) Cytokeratin 20 is not a reliable molecular marker for occult breast cancer cell detection in hematological tissues. Breast Cancer Res Treat 66:59-66

17. Watson MA, Fleming TP (1996) Mammaglobin, a mammaryspecific member of the uteroglobin gene family, is overexpressed in human breast cancer. Cancer Res 56:860-865
18. Watson MA, Dintzis S, Darrow CM et al (1999) Mammaglobin expression in primary, metastatic and occult breast cancer. Cancer Res 59:3028-3031

19. Nuñez-Villar MJ, Martinez-Arribas F, Pollán M et al (2003) Elevated mammaglobin (hMAM) expression in breast cancer is associated with clinical and biological features defining a less aggressive tumour phenotype. Breast Cancer Res. 5:R65-70

20. Min CJ, Tafra L, Verbanac KM (1998) Identification of superior markers for polymerase chain reaction detection of breast cancer metastases in sentinel lymph nodes. Cancer Res 58:4581-4584

21. Leygue E, Snell L, Dotzlaw H et al (1999) Mammaglobin, a potential marker of breast cancer nodal metastasis. J Pathol 189:28-33

22. Mitas M, Mikhitarian K, Walters C et al (2001) Quantitative realtime RT-PCR detection of breast cancer micrometastasis using a multigene marker panel. Int J Cancer 93:162-171

23. Zehentner BK, Dillon DC, Jiang Y et al (2002) Application of a multigene reverse transcription-PCR assay for detection of mammaglobin and complementarity transcribed genes in breast cancer lymph nodes. Clin Chem 48:1225-1231

24. Han JH, Kang Y, Shin HC et al (2003) Mammaglobin expression in lymph nodes is an important marker of metastatic breast carcinoma. Arch Pathol Lab Med 127:1330-1334

25. Gillanders WE, Mikhitarian K, Hebert R et al (2004) Molecular detection of micrometastatic breast cancer in histopathologynegative axillary lymph nodes correlates with traditional predictors of prognosis: an interim analysis of a prospective multiinstitutional cohort study. Ann Surg 239:828-840

26. Zach O, Kasparu H, Krieger O et al (1999) Detection of circulating mammary carcinoma cells in the peripheral blood of breast cancer patients via a nested reverse transcriptase polymerase chain reaction assay for mammaglobin mRNA. J Clin Oncol 17:2015-2019

27. Cerveira N, Torres L, Rocha P et al (2004) Highly sensitive detection of the MGB1 transcript (mammaglobin) in the peripheral blood of breast cancer patients. Int J Cancer 108:592-595

28. Silva AL, Tomé MJ, Correia AE, Passos-Coelho JL (2002) Human mammaglobin RT-PCR assay for detection of occult breast cancer cells in hematopoietic products. Ann Oncol 13:422-429

29. Diamond J, Goldman JM, Melo JV (1995) BCR-ABL, ABL$\mathrm{BCR}, \mathrm{BCR}$ and $\mathrm{ABL}$ genes are all expressed in chronic myeloid leukemia. Blood 85:2171-2175

30. Ring A, Smith IE, Dowsett M (2004) Circulating tumour cells in breast cancer. Lancet Oncol 5:79-88

31. Vannucchi AM, Bosi A, Glinz S et al (1998) Evaluation of breast tumour cell contamination in the bone marrow and leukapheresis collections by RT-PCR for cytokeratin-19 mRNA. Br J Hematol 103:610-617

32. Krag DN, Ashikaga T, Moss TJ et al (1999) Breast cancer cells in the blood: a pilot study. Breast J 5:354-358

33. Gilbey AM, Burnett D, Coleman RE, Holen I (2004) The detection of circulating breast cancer cells in blood. J Clin Pathol 57:903-911

34. O'Brien N, Maguire TM, O'Donovan N et al (2002) Mammaglobin: a promising marker for breast cancer. Clin Chem 48(1362): 1364

35. Grunewald K, Haun M, Urbanek M et al (2000) Mammaglobin gene expression: a superior marker of breast cancer cells in peripheral blood in comparison to epidermal-growth-factor receptor and cytokeratin-19. Lab Invest 80:1071-1077

36. Suchy B, Austrup F, Driesel G et al (2000) Detection of mammaglobin expressing cells in blood of breast cancer patients. Cancer Lett 158:171-178

37. Zehentner BK, Carter D (2004) Mammaglobin: a candidate diagnostic marker for breast cancer. Clin Biochem 37:249-257

38. Krüger WH, Jung R, Detlefsen B et al (2001) Interference of cytokeratin-20 and mammaglobin-reverse-transcriptase polymerase 
chain assays designed for the detection of disseminated cancer cells. Med Oncol 18:33-38

39. Grunewald K, Haun M, Fiegl M et al (2002) Mammaglobin expression in gynecologic malignancies and malignant effusions detected by nested reverse transcriptase-polymerase chain reaction. Lab Invest 82:1147-1153

40. Sjödin A, Guo D, Hofer PA et al (2003) Mammaglobin in normal human sweat glands and human sweat gland tumors. J Invest Dermatol 121:428-429

41. Ntoulia M, Stathopoulou A, Ignatiadis M et al (2006) Detection of mammaglobin A-mRNA-positive circulating tumor cells in peripheral blood of patients with operable breast cancer with nested RT-PCR. Clin Biochem 39:879-887

42. Roncella S, Ferro P, Bacigalupo B et al (2005) Human mammaglobin mRNA is a reliable molecular marker for detecting occult breast cancer cells in peripheral blood. J Exp Clin Cancer Res 24:265-271

43. Bustin SA, Benes V, Nolan T, Pfaffl MW (2005) Quantitative real-time RT-PCR-a perspective. J Mol Endocrinol 34:597-601

44. Gargano G, Agnese V, Calo V et al (2006) Detection and quantification of mammaglobin in the blood of breast cancer patients: can it be useful as a potential clinical marker? Preliminary results of a GOIM (Gruppo Oncologico dell'Italia Meridionale) a prospective study. Ann Oncol 17(Suppl 7):vii41vii45

45. Lin YC, Chen SC, Hsueh S et al (2003) Lack of correlation between expression of human mammaglobin mRNA in peripheral blood and known prognostic factors for breast cancer patients. Cancer Sci 94:99-102
46. Slamon DJ, Clark GM, Wong SG et al (1987) Human breast cancer: correlation of relapse and survival with amplification of the HER-2/neu oncogenes. Science 235:177-182

47. Mikhitarian K, Martin RH, Ruppel MB et al (2008) Detection of mammaglobin mRNA in peripheral blood is associated with high grade breast cancer: interim results of a prospective cohort study. BMC Cancer 8:55

48. Méhes G, Witt A, Kubista E, Ambros PF (2001) Circulating breast cancer cells are frequently apoptotic. Am J Pathol 159: 17-20

49. Saez RA, Mc Guire WL, Clark GM (1989) Prognostic factors in breast cancer. Semin Surg Oncol 5:102-110

50. Nemoto T, Natarjan N, Bedwani R et al (1983) Breast cancer in the medial half: results of the 1978 national survey of the American College of Surgeons. Cancer 51:1333-1338

51. Pantel K, Brakenhoff RH (2004) Dissecting the metastatic cascade. Nat Rev Cancer 4:448-456

52. Zlotnik A (2004) Chemokines in neoplastic progression. Semin Cancer Biol 181-185

53. Wiley H, Gonzalez E, Maki W et al (2001) Expression of CC chemokine receptor-7 and regional lymph node metastasis of B16 murine melanoma. J Natl Cancer Inst 93:1588-1589

54. Murakami T, Maki W, Cardones AR et al (2002) Expression of CXC chemokine receptor- 4 enhances the pulmonary metastatic potential of murine B16 melanoma cancer cells. Cancer Res 62:7328-7334

55. McShane LM, Altman DG, Sauerbrei W et al (2006) REporting recommendations for tumor MARKER prognostic studies (REMARK). Breast Cancer Res Treat 100:229-235 